\title{
ANAHEIM ACS SYMPOSIUM ON ELECTRON TRANSFER: COMPLEMENTARITY OF PHOTOCHEMISTRY AND RADIATION CHEMISTRY IN THE STUDY OF ELECTRON TRANSFER
}

\section{Schedule}

Tutorial: Radiation Chemistry Principles and Applications

Sunday, April 2nd, 1995, 8:55 am - 12:00 noon. J. F. Wishart, Presiding

8:55 James Wishart, Introductory Remarks

9:00 Helen Richter, University of Akron, Tutorial: Radiation Chemistry Principles and Applications

9:50 James Wishart, Brookhaven National Laboratory Accelerators and Other Sources for the Study of Radiation Chemistry

10:40 Alexander Trifunac, Argonne National Laboratory Detection of Transient Species in Radiation Chemistry

11:30 Morton Z. Hoffman, Boston University Chemistry of Radiation-Generated Intermediates

\section{Session 1: Electron Transfer in Metalloproteins}

Sunday, April 2nd, 1:25 - 5:30 pm., S. S. Isied, Presiding

1:25 D. Nocera and J. F. Wishart, Introductory Remarks

1:30 Harry Gray, California Institute of Technology Electron Tunneling in Proteins: Coupling Through a $\beta$-Strand

2:10 Israel Pecht, Weizmann Institute of Science, Israel Pathways and Control of Long-Range Electron Transfer Within Proteins

2:50 Brian Hoffman, Northwestern University Long-Range Electron Transfer Within Protein-Protein Complexes

3:30 James Wishart, Brookhaven National Laboratory Driving Force Dependence and Thermodynamics of Intramolecular Electron Transfer in Ammineruthenium-Modified, Native and Metal-Substituted Cytochromes c

4:10 Ann English, Concordia University, Canada Study of Oxyferryl Heme Reactivity using both Radiation and Photochemical Techniques

4:50 Bill Durham, University of Arkansas Free Energy Dependence of Electron Transfer in Cytochrome c Labeled with Ruthenium(II) Polypyridine Complexes

\section{Session 2: Electron Transfer in Bridged Donor-Acceptor Systems}

Monday, April 3rd, 1:30 - 5:30 pm., J. F. Wishart, Presiding

1:30 Stephan Isied, Rutgers, the State University of New Jersey Electron Transfer Across Peptide and Protein Matrices: Using the Full Time Domain of the Pulse Radiolysis Techniques

2:10 George McLendon, University of Rochester Photochemistry and Radiation Chemistry Studies of Intra Protein and Intra Peptide Electron Transfer

2:50 Krzysztof Bobrowski, Institute of Nuclear Chemistry and Technology, Warsaw, Poland Long Range Electron Transfer Between Proline-Bridged Aromatic Amino Acids

3:30 John Miller, Argonne National Laboratory Pulse Radiolysis Measurements of Intramolecular Electron Transfer

4:10 Thomas Moore, Arizona State University Photoinduced Electron Transfer and Proton Transfer in a Molecular Triad

4:50 Michael Wasielewski, Argonne National Laboratory Bridged Donor-Acceptor Molecules that Mimic the Radical Pair and Triplet States of Photosynthetic Reaction Centers 


\section{Session 3: Small-Molecule Electron Transfer and Activation}

Wednesday, April 5th, 8:40 am - 12 noon., R. van Eldik, Presiding

8:40 Diane Cabelli, Brookhaven National Laboratory Kinetic Studies of Superoxide with Manganese Complexes/Manganese Superoxide Dismutase

9:20 Klaus-Dieter Asmus, Hahn-Meitner-Institute, Berlin, Germany and the Notre Dame Radiation Laboratory Intermediates in the Oxidation of Cul(TTCN $)_{2}$ in Aqueous Solution

10:00 Carol Creutz, Brookhaven National Laboratory Mechanisms of Photochemical Reactions Elucidated by Pulse Radiolysis Experiments

10:40 James Espenson, Ames Laboratory, lowa State University Metal Radicals and Other Free Radicals: Electron Transfer Reactions

11:20 Noel Hush, University of Sydney, Australia The Primary Process in Photooxidation of $\mathrm{Fe}^{2+}$ in Water

\section{Session 4: Electron Transfer in Materials, Unusual Conditions and Ultrashort Timescales}

Wednesday, April 5th, 1:30 - 5:35 pm., D. Nocera, Presiding

1:30 Morton Z. Hoffman, Boston University Photoinduced Reduction of Tris(2,2'bipyrazine)ruthenium( ${ }^{(2+)}$ Ion in Aqueous Solution

2:10 Jacqueline Belloni, Université de Paris-Sud, France Kinetics of Electron Transfer Catalyzed by Metal Clusters

2:50 John Warman, Technical University of Delft, Netherlands Charge Migration and Recombination in Pulse-Irradiated Columnar Aggregates of Porphyrins and Phthalocyanines

3:30 Nicholas Turro, Columbia University Electron Transfer on Starburst Dendrimers and the Use of DNA as a Molecular Wire

4:10 Rudi van Eldik, University of Erlangen, Germany Electron Transfer Reactions Under High Pressure: Application of Spectroscopic and Electrochemical Techniques

4:50 Yann Gauduel, Laboratoire d'Optique Appliquée, Ecole Polytechnique - ENSTA, Palaiseau, France Ultrashort-Lived Pre-Chemical Steps in Aqueous Ionic Solutions

5:30 D. Nocera and J. F. Wishart, Closing Remarks

\section{Session 5: Contributed Talks}

Thursday, April 6th, 9:00 am - 11:40., D. Nocera, Presiding

9:00 Savitri Chandrasekhar, University of Saskatchewan Pulse Radiolytic Studies of the Redox Reactions of Pt(II) Macrocyclic Complexes

9:20 Etsuko Fujita, Brookhaven National Laboratory Toward Photoreduction of $\mathrm{CO}_{2}$ with $\mathrm{Ni}(\mathrm{bpy})_{n} 2+$ Complexes

9:40 Steven W. Keller, Penn State University Photochemically Induced Charge Separation in Electrostatically Constructed Organic-Inorganic Multilayer Composites

10:00 James A. Roberts, Michigan State University Photoinduced Electron Transfer Between an Acceptor Donor Pair Juxtaposed by a Salt Bridge

10:20 Piotr Piotrowiak, University of New Orleans Electrolyte Effects in Intramolecular Electron Transfer

10:40 H. Holden Thorp, University of North Carolina Electron Transfer Reactions Between DNA and Metal Complexes: Model Studies for lonizing Radiation Damage

11:00 David Wiedenfeld, California Institute of Technology Isotope Effects and Temperature Dependence of Intramolecular Electron-Transfer Reactions

11:20 Jeffrey Regan, University of California at San Diego Simple Theoretical Model to Predict the Influence of the Protein Environment on Tunneling Matrix Elements 